\title{
ERRATUM
}

K. K. Jena $\cdot$ J. U. Jeung $\cdot$ J. H. Lee $\cdot$ H. C. Choi

D. S. Brar

\section{High-resolution mapping of a new brown planthopper (BPH) resistance gene, Bph 18 (t), and marker-assisted selection for BPH resistance in rice (Oryza sativa $L$.)}

Published online: 10 January 2006

(C) Springer-Verlag 2006

\section{Theor Appl Genet (2006) 112:288-297}

Figure 2 and Table 5 were rendered incorrectly. The correct version are given here.

The online version of the original article can be found at http:// dx.doi.org/10.1007/s00122-005-0127-8

K. K. Jena $\cdot$ J. U. Jeung $\cdot$ D. S. Brar

Plant Breeding, Genetics, and Biotechnology Division,

International Rice Research Institute, DAPO Box 7777,

Metro Manila, Philippines

J. H. Lee · H. C. Choi · K. K. Jena $(\varangle) \cdot$ J. U. Jeung

Genetics and Breeding Division,

National Institute of Crop Science, RDA,

Suwon 441-857, South Korea

E-mail: kjena@rda.go.kr

Tel.: + 82-31-2906871

Fax: $+82-31-2948185$ 
A

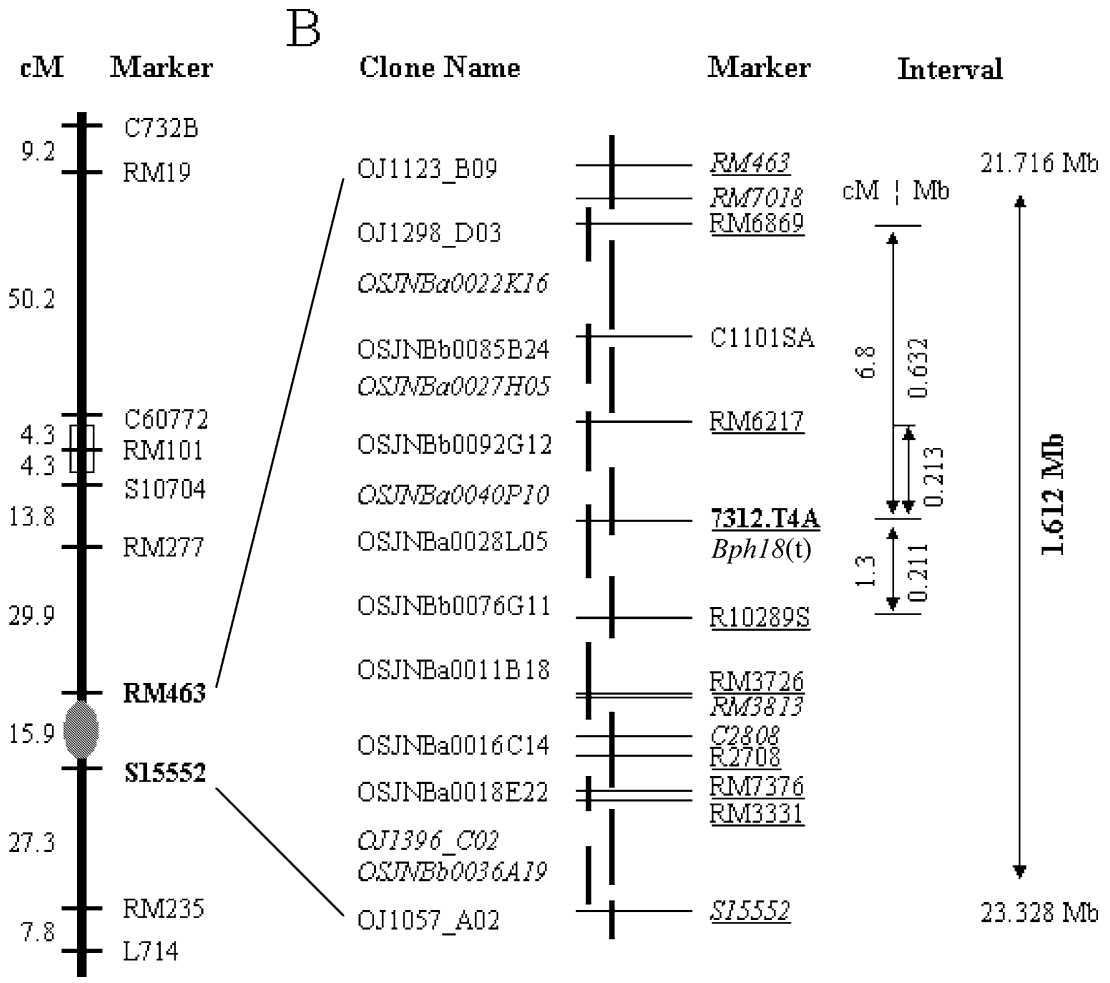

Fig. 2 a Linkage map skeleton of rice chromosome 12 showing ten polymorphic anchor markers and the putative R-gene location obtained by association analysis between marker genotypes of $\mathrm{F} 2$ progenies. Quantitative phenotyping of $\mathrm{F}_{3}$ lines (single-locus ANOVA) is indicated by two R- or S-associated markers (in boldface; RM463 and S15552). The open rectangle indicates the centromere region. b High-resolution map of $B p h 18(\mathrm{t})$ locus showing 15 Nipponbare BAC clones corresponding to the $15.9 \mathrm{cM}$ interval delimited by RM463 and S15552. The BAC clones, which were not tested with any DNA marker, are indicated in italics. The negative markers for the integration events of O. australiensis segmented into IR31917-45-3-2 (progenitor line) are indicated in italics. The R- or S-associated DNA markers, polymorphic between Jinbubyeo and IR65482-7-216-1-2, are underlined. The PCR primer set for the 7312.T4A (in boldface) marker tagging the $B p h 18(\mathrm{t})$ gene originated from Nipponbare BAC clone OSJNBa0028L05. The intervals between tested loci were estimated by using $94 \mathrm{~F}_{2}$ mapping populations and corresponding physical distances ( $\mathrm{cM}$ and $\mathrm{Mb}$ ) were calculated based on the genome sequence information of Nipponbare chromosome 12 
Table $5 e$-Landing procedure to determine the most putative chromosomal region of the Bph18(t) locus through bioassay of $\mathrm{F}_{2}$ progenies and genotyping susceptible progenies with DNA markers representing each BAC clone region

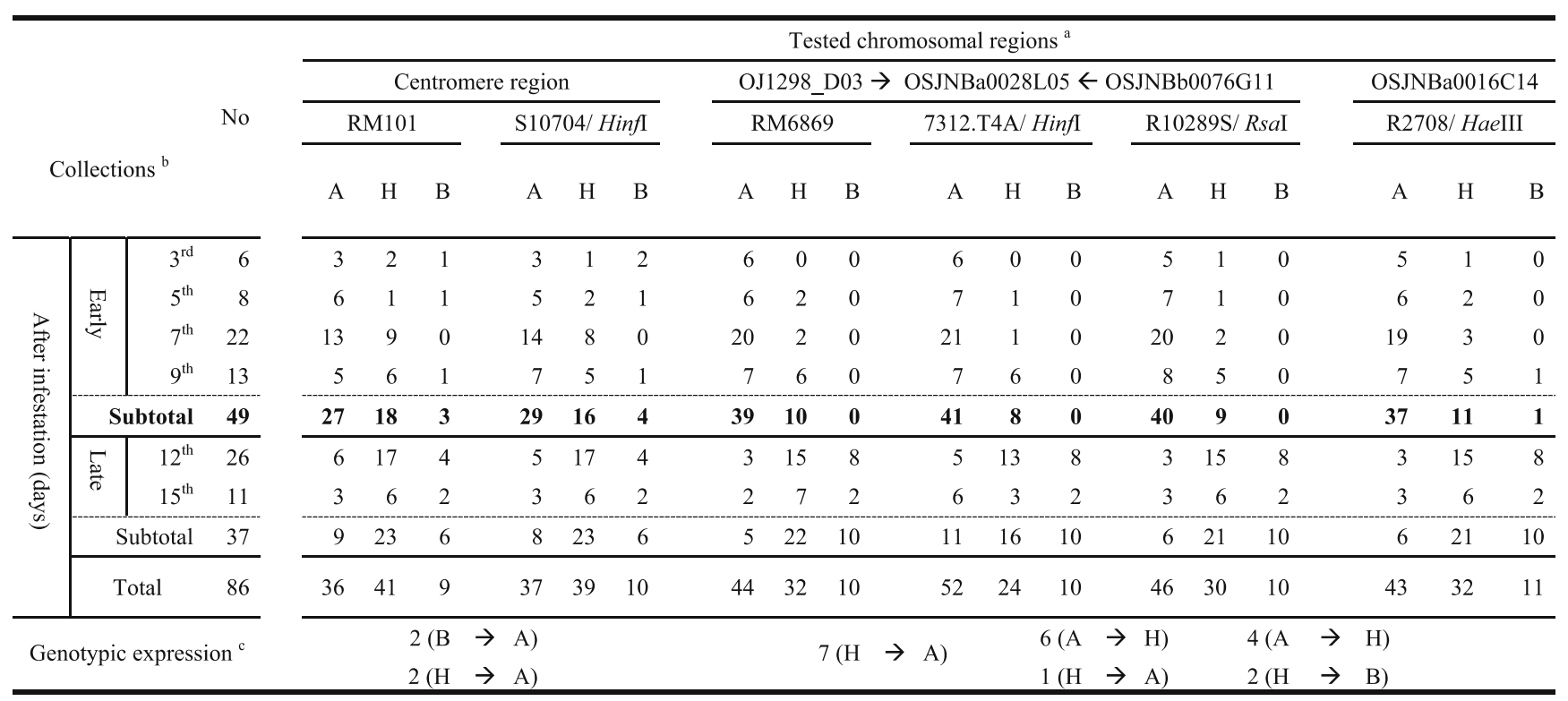

a Three chromosomal regions were selected for testing: 1) the presence of Bph10 near the centromere region, 2) the $1.056 \mathrm{Mb}$ interval delimited by two polymorphic DNA markers (RM6869 and R10289S) between the parental lines, Jinbubyeo and IR65482-7-216-1-2, and 3) another subterminal region tagged by R2708. The tested chromosomal regions are also illustrated in Fig. 2.

${ }^{\mathrm{b}}$ To optimize the screening duration for fine mapping of $B p h 18(\mathrm{t})$, time-based collection of susceptible seedlings was conducted. Out of $245 \mathrm{~F}_{2}$ seedlings tested, 86 susceptible seedlings were collected ( 6 time-point collections during 15 days after infestation). The genotyping data sets of 49 seedlings (until fourth-time collections) were used to judge the most putative location of $B p h 18(\mathrm{t})$. A and B are homozygous $\mathrm{F}_{2}$ individuals for Jinbubyeo and IR65482-7-216-1-2, respectively, and $\mathrm{H}$ is heterozygous individuals.

${ }^{c}$ All 86 collected seedlings were individually checked for the changed genotypes at each switching position of tested DNA markers. 